Cite this: RSC Advances, 2013, 3, 8131

Received 17th December 2012, Accepted 10th February 2013

DOI: 10.1039/c3ra23373a

www.rsc.org/advances

\section{Fucoidans from brown seaweeds: an update on structures, extraction techniques and use of enzymes as tools for structural elucidation}

\begin{abstract}
Marcel Tutor Ale and Anne S. Meyer*
Fucoidan or fucoidans cover a family of sulfated fucose-rich polysaccharides, built of a backbone of Lfucose units, and characteristically found in brown seaweeds. Fucoidans have potential therapeutic properties, including anti-inflammatory and anti-coagulant activities, as well as anti-proliferative effects on cancer cells. Recent work has revealed distinct structural features of fucoidans obtained from different brown seaweed sources. Fucoidans are classically obtained from brown seaweeds by multi-step, hot acid extraction, but the structural and compositional traits, and possibly the bioactivity, of the fucoidan polysaccharides are significantly influenced by the extraction parameters. This review discusses the structural features of fucoidans, the significance of different extraction technologies, and reviews enzymatic degradation of fucoidans and the use of fucoidan-modifying enzymes for elucidating structural details of fucoidans. Mild extraction techniques coupled with the use of new tools such as enzymes can provide the much needed knowledge about structural characteristics of different fucoidan molecules and thus pave the way for a better understanding of the structural chemistry and bioactivities of fucoidans.
\end{abstract}

\section{Introduction}

Marine seaweeds constitute an important part of the diet in many parts of Asia, and seaweeds have also been used in traditional medicine since prehistoric times. Seaweeds contain unique, hydrocolloid polysaccharide components such as alginate and carageenan that are used in many different food applications, but seaweeds are also a source of potentially bioactive polysaccharides, with fucoidans from brown seaweeds currently being the most intensely studied type of these compounds.

Fucoidans in fact designate a group of fucose-rich, sulfated polysaccharides, usually built of a backbone of $\alpha$-linked $\mathrm{L}^{-}$ fucose residues having various substitutions. Fucoidan polysaccharides are mainly found in brown seaweeds, but fucoidans differ in structure among brown seaweed species. Chemically, fucoidans cover several different structural entities that designate a family of fucose-containing sulfated polysaccharides (FCSPs). ${ }^{1}$ While FCSPs comprise many different types of fucose-rich polysaccharide structures, including sulfated fucogalacturonans found in e.g. Sargassum sp., we will in the present treatise use the terms fucoidan and fucoidan polysaccharides exclusively for structural polysaccharide components from brown seaweeds that have a backbone of $\alpha-\mathrm{L}^{-}$ fucopyranose residues. Fucoidan polysaccharides exhibit a

Center for Bioprocess Engineering, Department of Chemical and Biochemical Engineering, Technical University of Denmark (DTU), Building 229, DK-2800 Lyngby, Denmark.E-mail: am@kt.dtu.dk; Fax: +45 4593 2906; Tel: +45 45252800 number of pharmaceutically interesting biological activities, including immuno-modulatory, anti-tumor, anti-inflammatory and anti-coagulant effects (to be discussed in more detail later). The bioactivities of fucoidans are related to their structural make-up, monosaccharide composition, sulfate content, position of sulfate ester groups, and molecular weight. ${ }^{2}$ Mild extraction technology is essential for maintaining the structural integrity of the fucoidan polysaccharides and for preserving their biological properties.

Classical extraction of fucoidans from brown seaweeds involves multi-step extended aqueous extractions, usually with hot acid (hydrochloric acid), ${ }^{3}$ and may include calcium addition to promote alginate precipitation during purification, ${ }^{3,4}$ but no standardized purification procedure is available for fucoidans at present. Distinct structures can be isolated by different extraction conditions. ${ }^{2,5}$ It has recently been demonstrated that fucoidans are vulnerable to harsh extraction conditions and that the extraction method significantly influences the yields and not least the polysaccharide composition of the extracted fucose-containing sulfated polysaccharides. $^{3}$ In addition, the heterogeneity of the structural make-up of seaweeds within the same species may lead to pronounced differences in the products extracted. The problem of elucidating the structural details of fucoidans has been exacerbated by the use of many different extraction techniques. There is therefore an urgent demand for more well-defined, gentle extraction techniques, employing shortened extraction times, lower temperatures, and lower acid 
levels, to help ensure extraction of distinct structures of fucoidans. For industrial manufacturing, in addition to being consistent, the extraction technique must be cost-effective and eco-friendly, and of course abide appropriate legal requirements regarding solvent use.

This review provides an overview of the structural traits of fucoidans, highlights the extraction technologies used for obtaining fucoidans from brown seaweeds, and discusses the influence of extraction parameters on the yield and compositional attributes of fucoidan polysaccharides. Newer findings regarding fucoidan-modifying enzymes are discussed in relation to their action on fucoidans and their use in elucidating native fucoidan structures. Lastly, the potential bioactivities and possible applications of fucoidans are highlighted.

\section{Structures and chemical nature of fucoidans}

Fucoidans from brown seaweed algae generally consist of a backbone of $\alpha(1 \rightarrow 3)$-L-fucopyranose residues or of alternating $\alpha(1 \rightarrow 3)$ and $\alpha(1 \rightarrow 4)$-linked L-fucopyranosyls, which in either case may be substituted with sulfate or acetate and/or have side branches containing fucopyranoses or other glycosyl units, e.g. glucuronic acid. Several of the fucoidan structures reported in the literature have also contained small amounts of various other monosaccharides e.g. glucose, galactose, xylose, and/or mannose. ${ }^{1}$ These monosaccharides may represent contamination with other polysaccharides or may in fact be genuine substitutions on the fucoidan molecular entities.

The fucoidans in brown seaweeds in the order of Fucales, e.g. Fucus evanescens and Fucus serratus, represent the typical structures: They possess a large proportion of both $\alpha(1 \rightarrow 3)$ and $\alpha(1 \rightarrow 4)$-linked L-fucopyranose residues, which may be substituted with sulfate $\left(\mathrm{SO}_{3}{ }^{-}\right.$) on C-2 and C-4 (Table 1). ${ }^{6,7,10}$ Another typical fucoidan structure is found in fucoidans isolated from the alga Ascophyllum nodosum (Fucales). These fucoidan molecules have a backbone consisting of a repeating structure of $\alpha(1 \rightarrow 3)$-linked L-fucopyranose residues with sulfate at the $\mathrm{C}-2$ position, with the $\alpha(1 \rightarrow 3)$-linked $\mathrm{L}^{-}$ fucopyranose residues linked to $\alpha(1 \rightarrow 4)$-L-fucopyranose residues with disulfate at C-2 and C-3 (Table 1). The same structural elements are also found in fucoidans extracted from F. vesiculosus. ${ }^{9}$

In contrast, the sulfated "pseudo"-fucoidan polysaccharides extracted from some other species in the order Fucales, such as e.g. Sargassum stenophyllum, are built mainly of $\beta(1 \rightarrow 6)$-D-galactose and/or $\beta(1 \rightarrow 2)$-D-mannose units in the polysaccharide backbone with branching points formed by $\alpha(1 \rightarrow 3)$ and/or $\alpha(1 \rightarrow 4)$-L-fucose, $\alpha(1 \rightarrow 4)$-D-glucuronic acid, terminal $\beta$-D-xylose, and sometimes $\alpha(1 \rightarrow 4)$-D-glucose. The sulfate groups on the fucans are typically located at C-4 of a $(1 \rightarrow 3)$-linked unit or on $\mathrm{C}-2$ of a $(1 \rightarrow 4)$-linked residue. ${ }^{11}$

Several fucoidan structures extracted from brown seaweed species of the order of Laminariales have been reported to contain structural elements that mainly consist of a backbone of $\alpha(1 \rightarrow 3)$-linked L-fucopyranose residues with sulfates at the C-2 position. ${ }^{12,13}$ Fucoidans isolated from $L$. saccharina (Laminariales) are thus mainly composed of $\alpha(1 \rightarrow 3)$-linked Lfucopyranose units, but with sulfate at both C-2 and C-4, or at C-4 alone, however (Table 1). These structural units are similar to those found in the fucoidans from Chorda filum (Laminariales) which consist of a core backbone structure of poly- $\alpha(1 \rightarrow 3)$-linked L-fucopyranoses sulfated mainly at C-4, sometimes at the C-2 position, and with some of the $\alpha(1 \rightarrow 3)$ linked fucose residues being 2-O-acetylated. ${ }^{4,14}$ Similarly, the fucoidans from Cladosiphon okamuranus (Chordariales) are basically made up of linear backbones of $\alpha(1 \rightarrow 3)$-linked Lfucopyranose residues (Table 1) with a portion of the fucose residues being $\mathrm{O}$-acetylated and with some sulfate substitution at the C-4 position. ${ }^{8}$

Sulfated $\beta$-D-galactan has been isolated in trace amounts from Laminaria angustata and these polysaccharides have also been classified as fucoidans, eventhough $\beta$-D-galactose appear to be the major sugar, and L-fucose and D-glucuronic acid are present only as trace components. ${ }^{15}$

By use of advanced analytical technology more recent studies have verified that fucoidans from brown seaweeds in the order of Fucales such as $F$. evanescens and $F$. serratus do indeed contain large proportions of both $\alpha(1 \rightarrow 3)$ and $\alpha(1 \rightarrow 4)$ glycosidic bonds. ${ }^{6,7,10}$ Therefore the initial suggestion that fucoidan obtained from $F$. vesiculosus (Fucales) was built of $\alpha(1 \rightarrow 2)$ linked L-fucopyranosyl has been revised. ${ }^{16}$ More detailed analysis of $F$. evanescens by MALDI-TOF and tandem ESI mass spectrometry has also revealed the presence of minor components such as mixed mono-sulfated fucooligosaccharides containing both 2 - $O$ - and 4 - $O$-sulfated $(1 \rightarrow 4)$ bonded

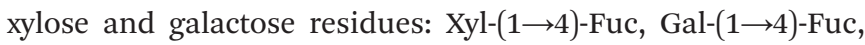
Gal-(1 $\rightarrow 4)$-Gal- $(1 \rightarrow 4)$-Fuc, Gal-( $1 \rightarrow 4)$-Gal. Glucuronic acid (GlcA) has also been detected and found to be an integral part of the non-sulfated fucooligosaccharides: Fuc- $(1 \rightarrow 3)-$ GlcA, Fuc- $(1 \rightarrow 4)$-Fuc- $(1 \rightarrow 3)$-GlcA, Fuc- $(1 \rightarrow 3)$-Fuc-( $1 \rightarrow 3)$-GlcA respectively. $^{13}$

The variations in the reported structural properties of fucoidans from different brown seaweed species clearly confirm the natural biodiversity of fucoidans as exemplified by the structures found in different seaweed taxonomical orders, notably Fucales, Laminariales and Chordariales (Table 1). It also seems clear that fucoidans extracted from brown seaweeds under the same seaweed classification (i.e. order) have different composition, and in turn that the structural traits cannot be categorized or predicted according to algal order as also indicated in Table 2.

Hence, the published structural data for algal fucoidans confirm that there is no consistent basic structure of "fucoidan".

Despite the relatively large variations in the compositional and structural properties of fucoidans obtained from different brown seaweed species, it appears that primarily the $(1 \rightarrow 3)$ linked $\alpha$-L-fucopyranosyl backbone structure, and secondly the backbone structure composed of alternating $\alpha(1 \rightarrow 3)$ and 
Table 1 Reported fucoidan structure obtained from different brown seaweed species of the order Chordariales, Laminariales, Ectocarpales and Fucales

\begin{tabular}{|c|c|c|c|}
\hline Seaweed species & Order & Fucoidan structural element & Notes \\
\hline Chorda filum & Laminariales & & $\begin{array}{l}\text { Contains a poly- } \alpha(1 \rightarrow 3) \text {-fucopyranose } \\
\text { backbone with a high degree of branching, } \\
\text { mainly of } \alpha(1 \rightarrow 2) \text {-linked single units. Sulfated } \\
\text { at } O-4 \text { (mainly) and } O-2 \text { positions. Some } \\
\alpha(1 \rightarrow 3) \text {-linked fucose residues are } 2 \text {-O-acetylated. }{ }^{4}\end{array}$ \\
\hline Laminaria saccharina & Laminariales & & $\begin{array}{l}\text { Mainly made up of } 4 \text {-sulfated } \alpha(1 \rightarrow 3) \text {-linked } \\
\text { a-L-fucopyranose residues, some of which are } \\
\text { additionally } 2 \text {-sulfated or carry a } 2-O-\alpha \text {-L-fucopyranosyl } \\
\text { substituent. }\end{array}$ \\
\hline
\end{tabular}

Fucus serratus $L$ Fucales

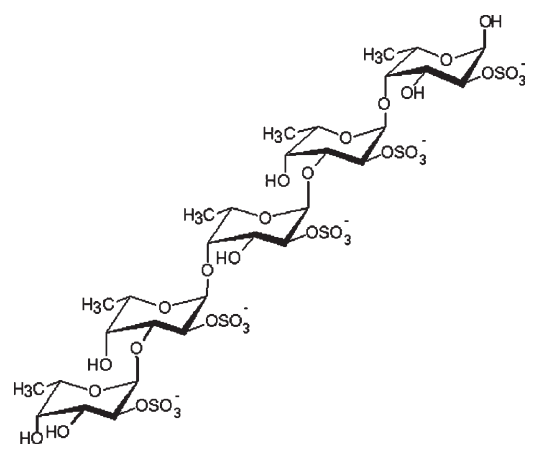

Cladosiphon okamuranus

Chordariales

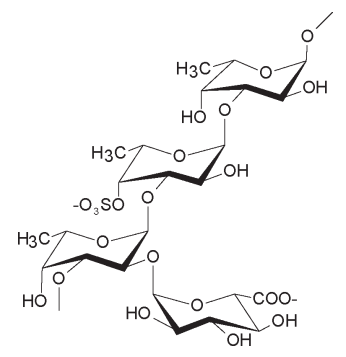

Ascophyllum nodosum
Fucales

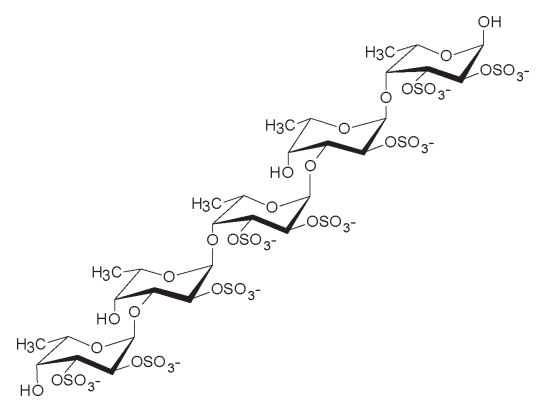

Contains a backbone built of alternating 3- and 4 -linked $\alpha$-L-fucopyranose moieties, with about half of the 3-linked residues being substituted at C- 4 by trifucoside units $\alpha$-L-Fucp-( $1 \rightarrow 4)-\alpha$-LFucp-( $1 \rightarrow 3)-\alpha$-L-Fucp-( $1 \rightarrow$ (not shown)). Sulfate groups have been shown to be substituted mainly on C-2 and sometimes C-4, although some terminal fucose residues may be nonsulfated. ${ }^{7}$

The main structure is a linear backbone of $\alpha(1 \rightarrow 3)$ fucopyranose with half of the sulfate substitutions at $\mathrm{C}-4$, and a portion of the fucose residues are $\mathrm{O}$-acetylated. The $\alpha$-glucuronic acid residues are linked to the $\mathrm{C}-2$ positions of the fucose residues which are not substituted by a sulfate group. ${ }^{8}$

An $\alpha(1 \rightarrow 3)$-linked fucose backbone and a high proportion of $\alpha(1 \rightarrow 4)$ linkages mainly sulfated at $\mathrm{O}-2$, to a lesser extent at $\mathrm{O}-3$, and only slightly at $\mathrm{O}-4$, and fucose 2, 3-O-disulfate residues were observed. Anticoagulant activity appears related to 2-O-sulfation and 2,3-O-disulfation levels. ${ }^{9}$ 
Table 2 Chemical composition of the different order of brown seaweed species produced using different extraction methods ${ }^{1}$

\begin{tabular}{|c|c|c|c|c|}
\hline Species & Order & Extraction Method & Composition & Reference \\
\hline $\begin{array}{l}\text { Cladosiphon } \\
\text { okamuranus }\end{array}$ & Chordariales & $\begin{array}{l}\text { Seaweed- } \mathrm{H}_{2} \mathrm{O} \text { suspension was } \\
\text { treated with } 30 \% \mathrm{HCl}(\mathrm{pH} 3) \\
\text { at } 100{ }^{\circ} \mathrm{C} \text { for } 15 \mathrm{~min} \text {. The } \\
\text { supernatant was neutralized } \\
\text { with } \mathrm{NaOH} \text {, precipitated } \\
\text { with } \mathrm{CaCl}_{2} \text { and EtOH for } \\
20 \mathrm{~h} \text { at } 4{ }^{\circ} \mathrm{C} \text {, precipitate was } \\
\text { dissolved with } \mathrm{H}_{2} \mathrm{O} \text { and } \\
\text { subsequently dried }\end{array}$ & $\begin{array}{l}\text { fucose, glucose, } \\
\text { uronic acid and sulfate }\end{array}$ & Nagaoka et al., (1999) ${ }^{8}$ \\
\hline $\begin{array}{l}\text { Sargassum } \\
\text { stenophyllum }\end{array}$ & Fucales & $\begin{array}{l}\text { Extracted with water } \\
7 \% \text { w/v ml, } 12 \mathrm{~h}, 3 \times \text {. } \\
\text { Precipitated with EtOH } \\
\text { and } \mathrm{CaCl}_{2} \text { and cetylpyridinium } \\
\text { chloride. Soluble fraction (SF) was } \\
\text { then fractionated (F1-F6) }\end{array}$ & $\begin{array}{l}\text { fucose, xylose, } \\
\text { mannose, galactose, } \\
\text { glucose, sulfate and uronic acid }\end{array}$ & Duarte et al., $(2001)^{11}$ \\
\hline $\begin{array}{l}\text { Fucus evanescens; } \\
\text { Fucus distichus }\end{array}$ & Fucales & $\begin{array}{l}\text { Pretreatment: } \mathrm{MeOH}-\mathrm{CHCl}_{3}-\mathrm{H}_{2} \mathrm{O} \\
(4: 2: 1) \text {, then extracted with } 2 \% \\
\mathrm{CaCl}_{2} \text { for } 5 \text { h at } 85{ }^{\circ} \mathrm{C} \text {, precipitated } \\
\text { and the precipitate was washed } \\
\text { with water, stirred with } 20 \% \\
\text { ethanolic solution and } \\
\text { dissolved with water }\end{array}$ & $\begin{array}{l}\text { fucose, xylose, galactose, } \\
\text { uronic acid and sulfate }\end{array}$ & Cumashi et al., $(2007)^{6}$ \\
\hline Fucus serratus & Fucales & $\begin{array}{l}\text { Pretreatment: } \mathrm{MeOH}-\mathrm{CHCl}_{3}-\mathrm{H}_{2} \mathrm{O} \\
(4: 2: 1) \text {, then extracted with } 2 \% \mathrm{CaCl}_{2} \\
\text { for } 5 \mathrm{~h} \text { at } 85{ }^{\circ} \mathrm{C} \text {, the extracts were } \\
\text { collected by centrifugation, combined, } \\
\text { dialyzed and lyophilized }\end{array}$ & $\begin{array}{l}\text { fucose, xylose, mannose, } \\
\text { glucose, galactose, } \\
\text { uronic acid and sulfate }\end{array}$ & Cumashi et al., $(2007)^{6}$ \\
\hline Chorda filum & Laminariales & $\begin{array}{l}\text { Extracted with } \mathrm{CHCl}_{3}-\mathrm{MeOH}-\mathrm{H}_{2} \mathrm{O} \\
(2: 4: 1) \text { followed by } 80 \% \text { EtOH, } \\
\text { then extracted successively with } 2 \% \\
\mathrm{CaCl}_{2} \text { at } 20 \text { and } 70{ }^{\circ} \mathrm{C} \text {, then with } \\
\mathrm{HCl}\left(\mathrm{pH} 2 \text { ) and } 3 \% \mathrm{Na}_{2} \mathrm{CO}_{3},\right. \\
\text { precipitated with calcium salt. }\end{array}$ & $\begin{array}{l}\text { fucose, xylose, mannose, } \\
\text { glucose, galactose, } \\
\text { uronic acid and sulfate }\end{array}$ & Chizhov et al., (1999) ${ }^{4}$ \\
\hline $\begin{array}{l}\text { Adenocystis } \\
\text { utricularis }\end{array}$ & Ectocapales & $\begin{array}{l}80 \% \mathrm{EtOH}, 24 \mathrm{~h}, 70{ }^{\circ} \mathrm{C} \text { pretreatment, } \\
\text { then extracted with water } \\
\text { (or } 2 \% \mathrm{CaCl}_{2} \text {; or } \mathrm{HCl} \text { ) for } 7 \mathrm{~h} \text {, room temp., } \\
\text { followed by exhaustive extraction at } 70{ }^{\circ} \mathrm{C}\end{array}$ & $\begin{array}{l}\text { fucose, rhamnose, glucose, } \\
\text { galactose, xylose, mannose, } \\
\text { uronic acid and sulfate }\end{array}$ & Ponce et al., $(2003)^{17}$ \\
\hline $\begin{array}{l}\text { Undaria } \\
\text { pinnatifida }\end{array}$ & Laminariales & $\begin{array}{l}\text { Ground seaweed extracted twice } \\
\text { at rt for } 6 \mathrm{~h} \text { with } 1 \% \mathrm{H}_{2} \mathrm{SO}_{4} \text {, neutralized } \\
\text { with } 10 \% \mathrm{NaOH} \text { and lyophilized }\end{array}$ & $\begin{array}{l}\text { fucose, mannose, xylose, } \\
\text { rhamnose, galactose, } \\
\text { glucose and sulfate }\end{array}$ & Hemmingson et al., $(2006)^{18}$ \\
\hline $\begin{array}{l}\text { Laminaria } \\
\text { religiosa }\end{array}$ & Laminariales & $\begin{array}{l}\text { Water extraction at boiling temp. } \\
\text { for } 4 \mathrm{~h} \text {, fucoidan fraction was obtained } \\
\text { by using } 0.09 \mathrm{HCl} \text { at } 4{ }^{\circ} \mathrm{C} \text { for } 2 \mathrm{~h} \text {, then } \\
\text { precipitated with } 85 \% \mathrm{EtOH} \text { and dried }\end{array}$ & $\begin{array}{l}\text { fucose, xylose, mannose, } \\
\text { glucose, rhamnose, } \\
\text { uronic acid and sulfate }\end{array}$ & $\begin{array}{l}\text { Maruyama and } \\
\text { Yamamoto }(1984)^{19}\end{array}$ \\
\hline
\end{tabular}

$\alpha(1 \rightarrow 4)$-linked L-fucopyranosyls, each with various extents of sulfate substitutions, are prevalent as the core backbone structures in the majority of fucoidan polysaccharides analyzed to date.

\section{History of fucoidan extraction technology}

Extraction using dilute acetic acid with subsequent purification of fucoidan polysaccharides was performed for the first time 100 years ago, in 1913, on various brown seaweeds, notably species of Laminaria and Fucus. ${ }^{20}$ Already then, Kylin ${ }^{20}$ reported that fucoidans extracted in this way mainly contained fucose. He also observed that the fucose occurred together with mannitol, alginic acid and laminarin; we now know that this interpretation was a result of co-extraction of these latter contaminants with the fucoidan polysaccharides. After two years of rigorous investigation, Kylin (1915) reported that fucoidan isolated from Laminaria digitata contained methylpentose, interpreted as L-fucose, as well as some other pentoses (Table 3). ${ }^{21}$ Nelson and Cretcher $(1931)^{22}$ used Macrocystis pyrifera as a fucoidan source, and employed repeated, extended ( $48 \mathrm{~h}$ ) extractions with dilute $\mathrm{HCl}$ followed by isolation of the fucoidan polysaccharides by ethanol precipitation (Table 3 ). Nelson and Cretcher $^{22}$ revealed the presence of sulfate in the form of ester groupings in the precipitated product and also confirmed that fucose was the only sugar present in the unhydrolyzed seaweed residue after acid hydrolysis-despite their product containing uronic acid (Table 3), which was considered to be due to alginate contamination. Alginate or alginic acid is composed of guluronic and mannuronic acids. In the past, these monomeric acid saccharides have been determined together as uronic acids, which cover several different structures, however. The presence of alginate (as a contaminant) in fucoidan polysaccharide extracts has caused some confusion in the 
Table 3 The development of fucoidan extraction methodology over the years (1913-1950s), and its influences on fucoidan polysaccharide composition from different brown seaweed species. Adapted from Ale et al. (2011) ${ }^{1}$

\begin{tabular}{|c|c|c|c|c|}
\hline Year & Brown Seaweed sp. & Reported FCSPs Composition & Extraction Method & References \\
\hline 1913 & Laminaria and Fucus & $\begin{array}{l}\text { Fucoidan contaminated } \\
\text { with mannitol, } \\
\text { alginate and laminaran }\end{array}$ & Dilute acetic acid extraction & Kylin $(1913)^{20}$ \\
\hline 1915 & Laminaria digitata & $\begin{array}{l}\text { Fucoidan contained methylpentose, } \\
\text { L-fucose, and some pentoses }\end{array}$ & Dilute acetic acid extraction & Kylin $(1915)^{21}$ \\
\hline 1915 & Macrocystis pyrifera & $\begin{array}{l}\text { Dominantly alginic acid, } \\
\text { with fucose-sulfate }\end{array}$ & $\begin{array}{l}\text { Seaweed was soaked in } \\
2 \% \mathrm{Na}_{2} \mathrm{CO}_{3} \text { for } 24 \mathrm{~h} \text {, } \\
\text { filtered, } \mathrm{HCl} \text { was added, } \\
\text { the precipitate filtered, } \\
\text { and then resolved in } 2 \% \mathrm{Na}_{2} \mathrm{CO}_{3}\end{array}$ & Hoagland and Lieb $(1915)^{26}$ \\
\hline 1931 & Laminaria digitata & $\begin{array}{l}\text { Substantial amounts of calcium } \\
\text { sulfate and uronic acid }\end{array}$ & $\begin{array}{l}\text { Soaking of seaweed in water, } \\
\text { precipitation of crude } \\
\text { sulfate by ethanol }\end{array}$ & Bird and Haas $(1931)^{23}$ \\
\hline 1931 & Macrocystis pyrifera & $\begin{array}{l}\text { Methylpentose monosulphate } \\
\text { polymer with mainly fucose } \\
\text { and alginate contaminants }\end{array}$ & $\begin{array}{l}\text { Repeated extraction with } \\
2 \% \mathrm{HCl} \text { at room } \\
\text { temperature for } 48 \mathrm{~h} \text {, } \\
\text { precipitated with } 90 \% \mathrm{EtOH} \text {. }\end{array}$ & Nelson and Cretcher $(1931)^{22}$ \\
\hline 1937 & Laminaria digitata & $\begin{array}{l}\text { Sulfate residue must be } \\
\text { substituted by fucose or } \\
\text { another sugar residue }\end{array}$ & $\begin{array}{l}\text { Prepared by precipitating } \\
\text { the droplets exuded from } \\
\text { seaweed in boiling ethanol }\end{array}$ & Lunde et al., $(1937)^{24}$ \\
\hline 1950 & $\begin{array}{l}\text { Fucus vesiculosus, } \\
\text { Fucus spirales, } \\
\text { Himanthalia lorea, } \\
\text { Laminaria clustoni }\end{array}$ & $\begin{array}{l}\text { Substantial amount } \\
\text { of fucose and sulfate; } \\
\text { and small amounts of uronic acid, } \\
\text { galactose and xylose; } \\
\text { ash was mainly calcium sulfate. }\end{array}$ & $\begin{array}{l}\text { Acid pH } 2-2.5,70{ }^{\circ} \mathrm{C} \\
\text { for } 1 \mathrm{~h}, 3 \text {-times; } \\
\text { or aqueous at } 100{ }^{\circ} \mathrm{C} \text { for } 24 \mathrm{~h} \text {, } \\
\text { lead acetate treatment, } \\
\text { barium hydroxide addition }\end{array}$ & Percival and Ross $(1950)^{25}$ \\
\hline 1952 & Fucus vesiculosus & Fucose, ash, sulfate & $\mathrm{pH} 2-2.5,70{ }^{\circ} \mathrm{C}$ for $1 \mathrm{~h}, 3$-times & Black et al., $(1952)^{27}$ \\
\hline
\end{tabular}

structural elucidation of fucoidan polysaccharides in the past. Bird and Haas (1931) obtained fucoidan from fresh fronds of Laminaria digitata by soaking the seaweed in water followed by precipitating crude sulfate from the extract with ethanol. ${ }^{23}$ Uronic acid was also present in the preparation (Table 3). Lunde et al., (1937) ${ }^{24}$ used fresh Laminaria digitata fronds and precipitation of the extracted fucoidan product using boiling ethanol. The extracted fucoidan specimen was found to contain $33-37 \%$ methylpentose (correctly interpreted as fucose), and the total sulfate estimated in the polysaccharide was $35-38 \%$ by weight. Later, boiling water was used to extract fucoidan polysaccharide fractions from Fucus vesiculosus, Fucus spirales, Himanthalia lorea and Laminaria clustoni by using $24 \mathrm{~h}$ extraction; and alginates and protein were removed with lead acetate and addition of barium hydroxide (Table 3 ). The resulting lead-hydroxide-fucoidan complex was then decomposed with dilute sulphuric acid, and the fucoidan molecules were isolated after prolonged hydrolysis and filtration. ${ }^{25}$ The product from Himanthalia lorea was considered the purest fucoidan specimen since it contained substantial amounts of fucose and sulfate. Still, small quantities of uronic acid, galactose and xylose were found. The ash was mainly composed of calcium sulfate.

Fucoidan production at the larger lab scale was done in the early 1950s to obtain larger quantities of fucoidans. ${ }^{27}$ The fucoidan extraction procedure was optimized by using one part by weight of dried ground seaweed and 10 parts by volume of $0.1 \mathrm{M} \mathrm{HCl}$ at $\mathrm{pH} 2.0-2.5$ contacted at $70{ }^{\circ} \mathrm{C}$ with constant stirring for $1 \mathrm{~h}^{27} \mathrm{~A}$ single acid hydrolysis extraction treatment using this method recovered about $50 \%$ by weight (w/w) of the theoretical maximum of the fucoidan polysaccharides (recovered yield measured as \% fucose obtained of total fucose present in the seaweed dry weight), whereas three rounds of the acid extraction recovered more than $80 \%$ of the fucose present; the triple acid hydrolysis treatment $(0.1 \mathrm{M} \mathrm{HCl}$, $\mathrm{pH} 2.0-2.5,70{ }^{\circ} \mathrm{C}, 1 \mathrm{~h} \times 3$ ) was therefore selected as the optimal extraction method. After the acid hydrolysis treatment the crude fucoidan polysaccharides were isolated by fractional precipitation with alcohol and further purified by precipitation after addition of formaldehyde. By this procedure, samples of crude fucoidans containing $30-36 \%$ fucose were obtained; for example, the fucoidan polysaccharides recovered from $F$. vesiculosus using this optimal extraction protocol was analyzed to contain (by weight) $44 \%$ fucose; $26 \%$ total sulfate, and $31 \%$ ash. Fucoidan yield was calculated as \% fucose of total fucose present in the seaweed raw material and the results obtained for the four different algal species were: Pelvetia canaliculata 76\%; F. vesiculosus 62\%; Ascophyllum nodusum 54\%, and $L$. cloustoni $20 \% .^{27}$ The triple-step $\mathrm{HCl}$ extraction procedure ${ }^{27}$ appears to be the one being used for the laboratory grade fucoidan product supplied by Sigma-Aldrich. However, already in the original report it was suggested that higher fucose yields might be achieved by increasing the solvent/seaweed ratio, extraction time or number of extractions.

The classical treatment with dilute acid at ambient or slightly elevated temperature is still a preferred first step in extraction protocols for isolating fucoidan from different types of brown seaweeds prior to any fractionation and purification process. $^{3}$ Transformation of alginate in the residual biomass 
into insoluble calcium salts by the aid of aqueous calcium chloride has been found to be a very useful technique. ${ }^{10}$

In recent years, inclusion of a pretreatment step prior to acid extraction has become common, especially for analysis of the (extracted) seaweed poly-saccharides. The pretreatment step involves contacting the seaweed with a mixture of methanol, chloroform and water (Table 2), and helps to eliminate low molecular components (e.g. phenols); ${ }^{7}$ removal of protein can be facilitated using proteolytic enzymes. ${ }^{28}$

Based on an analysis of the extraction methods employed in different studies, it has become clear that the use of different acids-or no acid at all- and differences in extraction time and temperature during the extraction and purification treatments of fucoidans, have generated very diverse compositional results and structural suggestions for fucoidan polysaccharides $^{1}$ (Tables 2 and 3 ).

A study was conducted to elucidate the structural components of a sulfated heteropolysaccharide obtained from Sargassum linifolium. The extraction was done using $\mathrm{HCl}$ at $\mathrm{pH} 1.0$ for $3 \mathrm{~h}$ at $80^{\circ} \mathrm{C}$; the extract was then neutralized with aqueous sodium carbonate and precipitated with ethanol. ${ }^{29}$ The resulting sulfated polysaccharide material was acid hydrolyzed and the structure was proposed to consist of a backbone composed of glucuronic acid, mannose, and galactose residues with partially sulfated side-chains composed of galactose, xylose and fucose residues. ${ }^{29} \mathrm{~A}$ similar brown seaweed species, Sargassum stenophyllum, was also extracted for fucoidans using water $(7 \% \mathrm{w} / \mathrm{v})$, for $12 \mathrm{~h}$-repeated $3 \times$ (Table 2), but the resulting sulfated polysaccharide material, termed "sargassan", was proposed to be built of glucuronic acid, mannose, and galactose residues with partially sulfated side-chains composed of galactose, xylose and fucose residues. ${ }^{11}$

\subsection{Influence of extraction parameters on fucoidan yield and composition}

The available compositional data evidently indicate the large variation in the composition of the fucoidan products obtained from different extraction methods. As already mentioned, the majority of extraction methods involve repetitive extraction in acid (i.e. $\mathrm{HCl}$ ) at elevated temperature.

To assess the influence of the extraction parameters notably acid, reaction time, temperature and repeated extraction on the yields and composition of the extracted fucoidan polysaccharides, we developed a single-step extraction procedure using Sargassum henslowianum as a model brown seaweed. ${ }^{3}$ All extraction parameters had significant effects on the yields, i.e. the fucose-containing sulfated polysaccharide yield, with the temperature and time exerting positive effects, and the acid concentration having a negative effect. A maximal fucoidan yield of $\sim 7 \%$ was achieved by the optimal extraction procedure of: $0.03 \mathrm{M} \mathrm{HCl}, 90{ }^{\circ} \mathrm{C}, 4 \mathrm{~h}$. Lower polysaccharide yield, but relatively higher fucose content was obtained with shorter extraction time.

The HPAEC-PAD analysis of the TFA hydrolysate of $S$. henslowianum confirmed that fucose, galactose, and glucuronic acid were the major constituents of the extracted polysaccharides obtained by the optimized method. ${ }^{3}$ The composition agrees with the prevalent polysaccharide structures known among the Sargassum species; hence, in the case of $S$. patens and S. stenophyllum ${ }^{30,31}$ fucose-containing elements have been found to contain a linear backbone built of $(1 \rightarrow 6)$ - $\beta$-D-galactose and/or $(1 \rightarrow 2)$ - $\beta$-D-mannose units with branched chains formed by $(1 \rightarrow 3)$ and/or $(1 \rightarrow 4)-\alpha-\mathrm{L}-\mathrm{fucose}$, $(1 \rightarrow 4)$ - $\alpha$-D-glucuronic acid, terminal $\beta$-D-xylose and sometimes $(1 \rightarrow 4)-\alpha$-D-glucose.

Structural integrity of the polysaccharide was best conserved at low acid treatment. The use of $0.2 \mathrm{M} \mathrm{HCl}$ apparently broke the integrity of the polysaccharide molecules resulting in a decline of fucose at elevated time and temperature. ${ }^{3}$ This indicated that the higher acid levels might have caused a loosening of the cell wall matrix allowing local penetration of the acid into the fucoidan. It has also been shown by others that longer extraction time at higher temperatures led to higher polysaccharide yield with lower amounts of sulfate and a higher proportion of glucuronic acid. ${ }^{11,17}$ Ponce et al. $(2003)^{17}$ thus reported that longer extraction time led to poorer fucose content, whereas glucuronic acid increased while sulfate decreased with time, i.e., the sulfate content was highest when glucuronic acid was lowest. ${ }^{17}$ We also noticed this trend during the experimental extraction work on $S$. henslowianum. ${ }^{3}$

The data demonstrate the vulnerability of fucoidan structures to harsh extraction conditions and confirm that the extraction method significantly influences the yields and not least the composition of the extracted polysaccharides.

The differences caused by differences in extraction methodologies obviously may have major bearings on the results when the fucoidan polysaccharide products are being evaluated for biological activity.

The available published data, including our own findings, thus generally show that the term "fucoidan" has been used for several chemical structures, and vice versa, that fucoidans is a term that covers a family of fucose-containing sulfated polysaccharides. It is therefore more correct to use the term fucose-containing sulfated polysaccharides (FCSPs) as a collective name for these polysaccharides. Also, a consensus to employ defined extraction protocols for extraction of fucoidan polysaccharides, or at least an agreement among. scientists in the field to always include a benchmark extraction procedure in their studies, would help to advance the understanding of these intriguing fucose-rich seaweed substances that exert unique bioactivities.

\section{Fucoidan modifying enzymes and their use for structural elucidation of fucoidans}

Enzymes catalyzing partial cleavage of seaweed polysaccharides, for instance fucoidanase and sulfatase, have been proposed to be useful tools for investigating the structural features and biological activity-function relationship of fucoidan polysaccharides. A number of studies, some of them originally initiated to study bacterial degradation of fucoidans have identified endo- and exo-type hydrolysis of fucoidan 
Table 4 Fucoidan structures from different brown seaweed sources catalysed by Fucoidanases obtained from different microorganisms and their mode of cleaving patterns. For simplicity, we have distinguished the cleavage patterns as type 1 and 2 for $(1 \rightarrow 4)-\alpha-L$-fucoidan endohydrolase and $(1 \rightarrow 3)-\alpha-L-f u c o i d a n$ endohydrolase, respectively (Fig. 1); and the exo-action as type 3 (Fig. 1)

\begin{tabular}{|c|c|c|c|c|}
\hline Fucoidanases source & Fucoidan source & Fucoidan structures & Cleaving pattern & Reference \\
\hline $\begin{array}{l}\text { Mariniflexile } \\
\text { fucanivorans SW5 }\end{array}$ & Pelvetia canaliculata & $\begin{array}{l}{[3)-\alpha-\mathrm{L}-\text { fucp- }\left(2 \mathrm{SO}_{3}{ }^{-}\right)-(1 \rightarrow 4)-\alpha-\mathrm{L}-\text { fucp- }} \\
\left(2,3 \mathrm{SO}_{3}{ }^{-}\right)-(1 \rightarrow] \text { repeating units }\end{array}$ & $\begin{array}{l}(1 \rightarrow 4)-\alpha \text {-L-fucoidan } \\
\text { endohydrolase } \\
\text { (Enzyme type } 1)\end{array}$ & Descamps $(2006)^{32}$ \\
\hline $\begin{array}{l}\text { Fucophilus } \\
\text { fucoidanolyticus }\end{array}$ & Cladosiphon okamuranus & 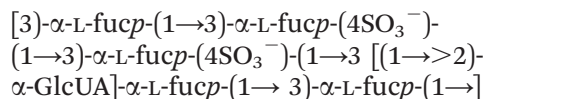 & $\begin{array}{l}(1 \rightarrow 3)-\alpha \text {-glycosidic } \\
\text { bonds in fucoidan } \\
\text { (Enzyme type } 2 \text { ) }\end{array}$ & Sakai $(2003)^{33}$ \\
\hline $\begin{array}{l}\text { Fucanobacter } \\
\text { marina SA-0082 }\end{array}$ & Kjellmaniella crassifolia & $\begin{array}{l}{[\rightarrow 3)-\alpha-\mathrm{L}-\text { Fuc } p-(1 \rightarrow 3)-\alpha-\mathrm{L}-\mathrm{Fuc} p-(1 \rightarrow 3)-\alpha-\mathrm{L}-} \\
\text { Fucp- }(1 \rightarrow 3)-\alpha-\mathrm{L}-\mathrm{Fuc} p-(1 \rightarrow] ; \text { branching mainly } \\
\text { of }(1 \rightarrow>2)-\alpha-\mathrm{L}-\text { Fuc } p \text { single units }\end{array}$ & $\begin{array}{l}(1 \rightarrow 3)-\alpha \text {-L-glycosidic } \\
\text { bonds in fucoidan } \\
\text { (Enzyme type } 2 \text { ) }\end{array}$ & Sakai $(2002)^{34}$ \\
\hline Littorina kurila & Fucus distichus & $\begin{array}{l}{[3)-\alpha-\mathrm{L}-\text { Fucp }-\left(2,4 \mathrm{SO}_{3}{ }^{-}\right)-(1 \rightarrow 4)-\alpha-\mathrm{L}-\mathrm{Fuc} p-\left(2 \mathrm{SO}_{3}{ }^{-}\right)-} \\
(1 \rightarrow] \text { repeating units }\end{array}$ & $\begin{array}{l}\text { hydrolyzed some } \\
\text { glycosidic bonds in } \\
\text { fucoidan molecules }\end{array}$ & Bilan $(2005)^{35}$ \\
\hline $\begin{array}{l}\text { Pseudoalteromonas } \\
\text { citrea KMM } 3296\end{array}$ & Fucus evanescens & $\begin{array}{l}{[3)-\alpha-\mathrm{L}-\text { fucp- }\left(2 \mathrm{SO}_{3}{ }^{-}\right)-(1 \rightarrow 4)-\alpha-\mathrm{L} \text {-fucp- }\left(2 \mathrm{SO}_{3}{ }^{-}\right)-} \\
(1 \rightarrow] \text { repeating units }\end{array}$ & $\begin{array}{l}(1 \rightarrow 3)-\alpha-\mathrm{L}-\mathrm{fucoidan} \\
\text { endohydrolase } \\
\text { (Enzyme type } 2 \text { ) }\end{array}$ & Bakunina $(2002)^{36}$ \\
\hline $\begin{array}{l}\text { Pseudoalteromonas } \\
\text { citrea } \mathrm{KMM} 3298\end{array}$ & Chorda filum & $\begin{array}{l}{[\rightarrow 3)-\alpha \text {-L-Fuc } p-(1 \rightarrow 3)-\alpha \text {-L-Fucp- }(1 \rightarrow 3)-\alpha-\mathrm{L}-\text { Fuc } p \text { - }} \\
(1 \rightarrow 3)-\alpha \text {-L-Fucp- }(1 \rightarrow 3)-\alpha \text {-L-Fucp- }(1 \rightarrow] ; \text { sulfated } \\
\text { groups at C2 and C4; branching mainly of } \\
(1 \rightarrow 2)-\alpha \text {-L-Fuc } p \text { single units }\end{array}$ & $\begin{array}{l}(1 \rightarrow 3)-\alpha \text {-L-fucoidan } \\
\text { endo-hydrolase } \\
\text { (Enzyme type } 2) ; \\
\text { resulting product: } \\
\text { sulfated } \alpha \text {-L- } \\
\text { fucooligosaccharides }\end{array}$ & Bakunina $(2002)^{36}$ \\
\hline Vibrio sp. N-5 & Kjellmaniella crassifolia & $\begin{array}{l}{[\rightarrow 3)-\alpha \text {-L-Fucp- }(1 \rightarrow 3)-\alpha \text {-L-Fucp- }(1 \rightarrow 3)-\alpha-\mathrm{L} \text {-Fucp- }} \\
(1 \rightarrow 3)-\alpha \text {-L-Fucp- }(1 \rightarrow] ; \text { branching mainly } \\
\text { of }(1 \rightarrow 2)-\alpha \text {-L-Fuc } p \text { single units }\end{array}$ & $\begin{array}{l}\text { Exo-type fucoidanases; } \\
\text { main products: monomers } \\
\text { and dimers of sulfated } \\
\text { L-fucose (Enzyme type } 3 \text { ) }\end{array}$ & Furukawa $(1992)^{37}$ \\
\hline Pecten maximus & Ascophyllum nodosum & $\begin{array}{l}{[3)-\alpha-\mathrm{L} \text {-fucp- }\left(2 \mathrm{SO}_{3}{ }^{-}\right)-(1 \rightarrow 4)-\alpha-\mathrm{L}-\mathrm{fuc} p-\left(2,3 \mathrm{SO}_{3}{ }^{-}\right)-} \\
(1 \rightarrow] \text { repeating units }\end{array}$ & $\begin{array}{l}(1 \rightarrow 4)-\alpha-\mathrm{L}-\text { fucose } \\
\text { glycosidic bonds } \\
\text { (Enzyme type } 1)\end{array}$ & Berteau $(2002)^{38}$ \\
\hline
\end{tabular}

polysaccharides. During the last 10 years the enzymes have been used as an aid in investigating structural features of fucoidans.

\subsection{Fucoidan modifying enzymes}

Enzymes catalyzing modifications of fucoidan polysaccharides, i.e. "fucoidanases", include: $i$ ) Fucoidanases, EC 3.2.1.44, which catalyze the endo-hydrolysis of $(1 \rightarrow 2)$ - $\alpha$-L-fucoside linkages in fucoidans without release of sulfate, and ii) $\alpha$-LFucosidases, EC 3.2.1.51 which catalyze the hydrolytic release of L-fucose, via cleavage of $\alpha(1 \rightarrow 3)-, \alpha(1 \rightarrow 4)$ - and possibly also of $\alpha(1 \rightarrow 2)$-O-fucosyl bonds in fucoidan oligosaccharides. The enzymatic cleaving pattern and the structures of the products obtained from various fucoidan seaweed sources by the action of different types of fucoidanases from different microorganisms are listed in Table 4 and illustrated in Fig. $1 .^{32-38}$

Enzyme-assisted extraction of fucoidan polysaccharides has recently been proposed, ${ }^{5}$ using enzymes that do not catalyze the hydrolysis of the target fucoidan polysaccharides. Enzyme assisted extraction is a clean and green type of technology. However, as compared to the quite advanced stage of development of designed enzyme mixtures for hydrolysis of complex plant materials or heterogenous plant cell wall polysaccharides, ${ }^{39,40}$ only various crude, commercial enzyme mixtures, designed for plant material processing, have been used as hydrolysis aids for extraction of brown seaweed biofunctional polysaccharide fractions. ${ }^{5,41}$ On the other hand, fucoidanases have been intensely studied in relation to bacterial degradation of fucoidans and molecular structure elucidation of fucoidan polysaccharides. ${ }^{35,36,42}$ A study of the fucosidase action on fucoidan polysaccharides from Fucus distichus has thus established that the native fucoidan polysaccharides contain blocks of acetylated and partially sulfated repeating units. ${ }^{35}$ Likewise, the enzymatic treatment confirmed that the main fucoidan structural unit from this brown seaweed Fucus spp. consists of repeating di-saccharide units of $[\rightarrow 3)-\alpha-\mathrm{L}-\mathrm{Fuc} p-\left(2,4 \mathrm{di}_{-} \mathrm{SO}_{3}{ }^{-}\right)-(1 \rightarrow 4)-\alpha-\mathrm{L}-\mathrm{Fuc} p-\left(2 \mathrm{SO}_{3}{ }^{-}\right)$$(1 \rightarrow] .^{35}$

Three different cleavage mechanisms for fucoidan polysaccharides are principally known to date: $\alpha$-L-fucosidase only catalyses the cleavage the $\alpha$-L-fucosyl linkages at the nonreducing termini, releasing fucose from the fucose-backbone structure in fucoidans (Enzyme type 3, Fig. 1). For fucoidanases there are two different types of mechanisms known: one type of fucoidanase catalyses the cleavage of small, low molecular weight oligosaccharides from the end of the fucoidan backbone chains while the other type of fucoidanase catalyses the glycosidic bonds (both $\alpha(1 \rightarrow 3)$-, $\alpha(1 \rightarrow 4)$-bonds) in the fucose-back bone via random endo-type hydrolysis (Table 4). ${ }^{32-38}$ We have chosen to differentiate these two types of enzymatic endo-attack as type 1 for $\alpha(1 \rightarrow 4)$ cleavage, and type 2 for the $\alpha(1 \rightarrow 3)$ cleavage (Table 4 and Fig. 1$)$.

Fucoidanase activities were first detected in several different marine microorganisms, including marine bacteria such as Vibrio sp., Alteromonas sp., Pseudoalteromonas sp., and bacteria of the family Flavobacteriaceae. ${ }^{32,36,37,43}$ Twenty five strains of epiphytic marine bacteria obtained from brown seaweed and 53 bacteria isolated from sea cucumber were also screened for 


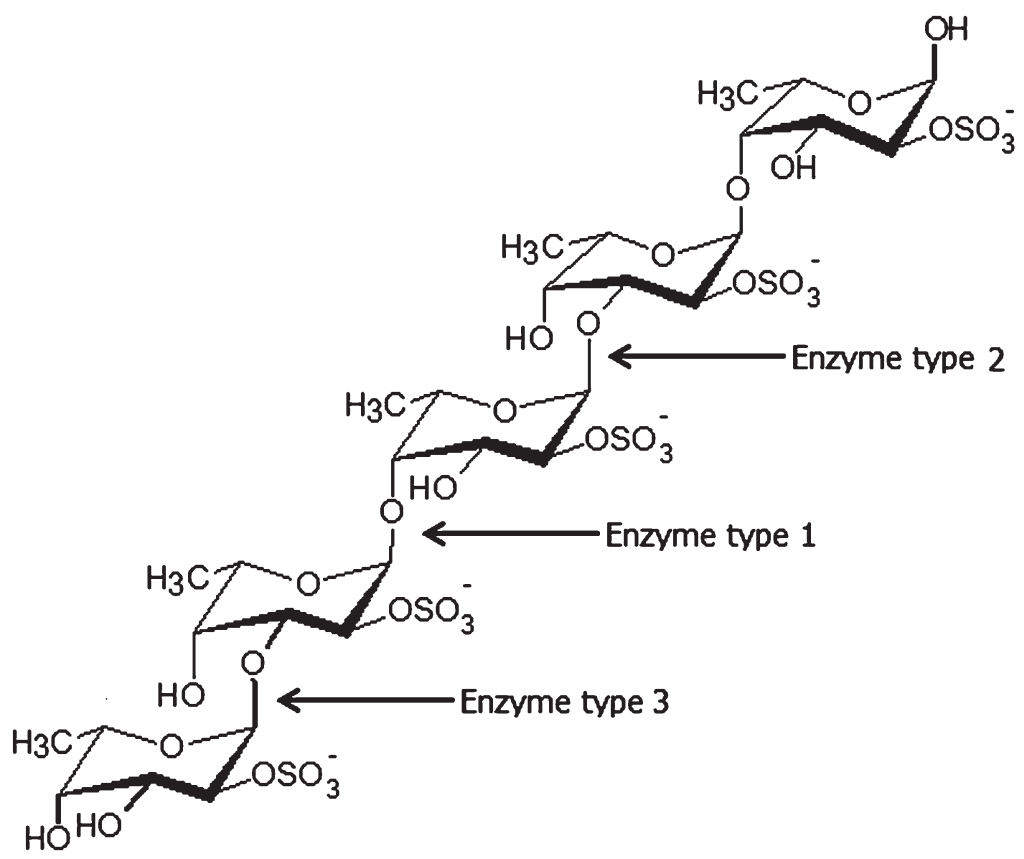

Fig. 1 Enzymatic attack patterns of $\alpha$-L-fucoidan endohydrolase and fucosidase, respectively: For simplicity, we have distinguished the cleavage patterns as type 1 for $(1 \rightarrow 4)$ - $\alpha$-L-fucoidan endohydrolase and type 2 for $(1 \rightarrow 3)$ - $\alpha$-L-fucoidan endohydrolase; and the exo-action, EC 3.2.1.51, as type 3. (Since the EC 3.2.1.44 fucoidanase activity only designates catalysis of the endo-hydrolysis of $(1 \rightarrow 2)-\alpha$-L-fucosides, the enzymes type 1 and type $2 \alpha-L$-fucoidan endohydrolases are in principle not EC categorized.) References in Table 4.

efficient fucoidanase production. Bacteria of the genera Cytophaga and Alteromonas/Pseudoalteromonas exhibited the highest fucoidanase activities. ${ }^{36}$

Fucoidan structures of brown seaweeds from the orders Fucales and Chordariales are known to differ from those of Laminariales. ${ }^{1}$ The L-fucopyranose backbone of the fucoidan extracted from A. nodosum and $F$. vesiculosus is connected by alternating $\alpha(1 \rightarrow 3)$ and $\alpha(1 \rightarrow 4)$ linkages with sulfate substituted at the 2- and 3-position of the fucose residues while fucoidan of Chorda filum and Laminaria saccharina consist of a poly- $\alpha$-(1 $\rightarrow 3)$-fucopyranoside backbone with sulfate mainly at $\mathrm{C}-4$ and sometimes at the $\mathrm{C}-2$ position (Table 1). Fucoidanase from the marine bacterium Fucanobacter lyticus has shown to exhibit extracellular endo-fucoidanase degrading activity on fucoidan polysaccharides obtained from brown seaweed in the order of Laminariales but not Fucales and Chordariales indicating specificity of an endo-1,3- $\alpha$-fucoidanase. ${ }^{44}$ Marine bacteria such as Fucophilus fucoidanolyticus are to a certain extent able to consume fucoidans of various structures and apparently synthesize a number of fucoidan-degrading enzymes. At least one of them (intracellular fucoidanase) seems to have the ability to catalyse the splitting of 1,3$\alpha$-glycosidic bonds and has also been demonstrated to express deacetylase activity being effective on acetylated fucoidans from Cladosiphon okamuranus. ${ }^{33}$

From the information available about enzymes able to catalyse modification of fucoidans from brown seaweeds, it appears that these enzymes may have a broad spectrum of biological roles and potential applications. As mentioned earlier, fucoidan polysaccharides and other FCSPs exhibit significant biological properties in vitro such as anti-prolif- erative activity on cancer cells. However, the exact structural element(s) in the fucoidan molecules being responsible for these potentially protective activities are still unidentified. In this connection, the targeted use of fucoidanases might assist in determining the precise molecular structures accountable for preventive bioactivity effects. Also, as proposed by Holtkamp et al. (2009) ${ }^{42}$ more knowledge about the fucoidan-degrading enzymes might help in the elucidation of different fucoidan structures and could pave the way for use of these enzymes in industrial processes.

\section{The prospects for seaweed polysaccharides from brown seaweeds}

Fucoidan polysaccharides have been reported to have potential beneficial bioactive functions, including anti-proliferative effects on certain types of cancer cells. ${ }^{45}$ The biological activity of fucoidans depend on the seaweed source, the compositional and structural traits, the content (charge density), distribution, and bonding of the sulfate substitutions, and the purity of the fucoidan product. Thus the extraction process employed for the fucoidans is crucially important for maintaining the structural integrity and the relevant structural features required for specific biological activity. A consistent extraction process is also a prerequisite for elucidating the structurefunction relationship that promotes these biological properties. The lack of a standardized extraction methodology prevents detailed comparison and most importantly obstructs the understanding of the correlation between fucoidan 
polysaccharide structures and biological functions. As a consequence, no pharmaceutical, dermatological, nutraceutical or other applications have as yet been officially approved for these polysaccharides or their lower molar mass oligosaccharide derivatives. Nevertheless, fucoidan capsules are marketed as nutracuetical supplements, and seaweed extracts have been used as a remedy in traditional medicine in parts of Asia, notably in Japan, the Philippines, and Koreas for centuries.

\subsection{Fucoidan bioactivity and potential applications}

Algal fucoidans have been the subject of numerous scientific studies due to their diverse biological functions and possible therapeutic properties including antitumor, immunomodulatory, ${ }^{45}$ anti-inflammatory, ${ }^{6}$ antithrombotic, and anticoagulant effects. ${ }^{46}$ The direct anti-proliferative effects of fucoidan polysaccharides against certain cancer cells have been shown in vitro using cell viability analysis. Both FCSPs from Sargassum sp. and more classic fucoidan polysaccahrides from Fucus vesiculosus significantly decreased the viable number of lung carcinoma and melanoma cells in vitro in a doseresponse fashion. ${ }^{45}$ Histochemical staining showed morphological changes of melanoma cells after exposure to the fucoidans and were indicative of crude fucoidan induced apoptosis. ${ }^{45}$ Fucoidan was also reported to induce apoptosis in HT-29 colon cancer cells, ${ }^{47}$ MCF-7 human breast cancer cells, ${ }^{48}$ and HS-Sultan human lymphoma cells. ${ }^{49}$ It has been suggested that the bioactive properties of fucoidans are defined by their structural make-up, and notably related to the fucose sulfated chains. ${ }^{15}$ Nevertheless, it appears that the anti-cancer activity of fucoidans is not a function of a single specific structural trait but a combination of many factors such as the amount of sulfate groups, the monosaccharide composition, and the types of linkages of the sugar residues. ${ }^{1,30}$ Some findings indicate that the antitumor activity of fucoidan is a result of an indirect effect which may be associated with a significant enhancement of the cytolytic activity of natural killer (NK) cells augmented by increased production of macrophage-mediated immune response signaling molecules, ${ }^{50,51}$ namely interleukins (IL)-2, IFN- $\gamma$ and IL12. ${ }^{50}$ Hence, stimulation with IL-2 and IL-12 may promote the secretion of IFN- $\gamma$ by NK cells, probably via enhanced NK cell activity by fucoidan.

The bioactive properties of fucoidans currently attract research institutions and private companies to undertake comprehensive investigations for potential applications of fucoidan molecules in the nutraceutical food ingredients industry and in the cosmetic industry. In the USA and UK, fucoidan is already commercially available as health supplements in the form of beverages and tablets which are mostly marketed over the internet. Brown seaweeds like Cladosiphon okamuranus (Mozuku) and Undaria pinnatifida (Mekabu), and Laminaria japonica (Kombu) are the most important sources of fucoidans in Japan. The company Kanefuku Co, Ltd, Japan produces and supplies fucoidan polysaccharides (Umi No Shizuku) as a dietary supplement in the form of powder, capsules and drinks to enhance the immune system and increase longevity. Fucoidan products from Takara Bio Inc,
Japan are marketed as an anti-inflammatory and immuneboosting formulation and used in nutritional drinks and functional foods. Production of pure fucoidan products is challenging because of the presence of other polysaccharides, such as alginate. In Korea, Seaherb Co. Ltd. has patented a technology for the manufacture of low molecular weight fucoidan saccharides aimed at increasing absorption rate. However, this technology does not remove other polysaccharide impurities but only degrades large molecular size compounds (including contaminants such as alginate) to reduce the molecular sizes of the polysaccharides in the final crude fucoidan product.

Applicability of fucoidans as "cosmeceuticals" in the cosmetic industry has also been studied. Most of these studies focus on the inhibitory effects of topically applied fucoidans on aging and photo-damaged skin. Fucoidans may enhance dermal fibroblast proliferation and deposition of collagen; ${ }^{52}$ protect the elastic fiber network in human skin culture; ${ }^{53}$ and to have potential for inclusion in lotion as a natural whitening agent. ${ }^{54}$ The prospects of using fucoidans as a protective agent in topical cosmetic formulations thus seem very promising. Since fucoidans are water soluble, they can easily be incorporated into lotions, creams and other beauty products. As a pharmaceutical or nutraceutical ingredient, fucoidans clearly offer distinctive possibilities for immuno-modulation and anti-cancer effects.

\section{Conclusions and outlook}

Brown seaweed is an important source of valuable technofunctional and potentially bioactive polysaccharides. Among the polysaccharides from brown seaweeds, fucoidans have turned out to exert potentially significant pharmaceutical effects, but at the same time to be a family of differently structured polysaccharides comprising structural units having distinct traits. Despite intensive research, the exact correlations between the various bioactivities and the molecular and structural features of fucoidans still have to be clarified. It is known now that the fine structural details of fucoidans vary depending on seaweed type and species. Fucoidanases may provide new tools for elucidation of detailed fucoidan structures from various sources. Preservation of the structural integrity of the fucoidan molecules appears crucial for maintaining their biological properties. It has been convincingly shown that the extraction treatment employed affects the composition and thus the structural features of the fucoidan substances. It is also clear that acid treatment used as the major step/steps in the extraction of fucoidans causes degradation and affects the integrity of overall fucoidan makeup. Thus milder extraction procedures must be implemented in order to preserve the native fucoidan structures in order to bring out the distinct biological properties. The extraction methodology employed may thus significantly affect the results obtained when the fucoidan products are being evaluated for biological activity. Despite the availability of early, seminal studies on fucoidans, the understanding of 
their complex structures still requires more research. However, the potential biological effects and the application possibilities for fucoidans seem promising.

Harsh chemicals are environmentally burdensome and have detrimental effects on the yield and compositions of the end product polysaccharides. These facts call for implementation of milder and greener extraction technologies for fucoidan polysaccharides from brown seaweeds. Seaweeds may in general represent a renewable biomass source that can be cultivated for sustainable processes and products. More research is warranted to improve extraction and purification of defined fucoidan polysaccharide structures from brown seaweeds using gentler methods especially in relation to scale-up for industrial production.

\section{References}

1 M. T. Ale, J. D. Mikkelsen and A. S. Meyer, Mar. Drugs, 2011, 9, 2106-2130.

2 B. Li, F. Lu, X. Wei and R. Zhao, Molecules, 2008, 13, 1671-1695.

3 M. T. Ale, J. D. Mikkelsen and A. S. Meyer, J. Appl. Phycol., 2012, 24, 715-723.

4 A. O. Chizhov, A. Dell, H. R. Morris, S. M. Haslam, R. A. McDowell, A. S. Shashkov, N. E. Nifant'ev, E. A. Khatuntseva and A. I. Usov, Carbohydr. Res., 1999, 320, 108-119.

5 T. Hahn, S. Lang, R. Ulber and K. Muffler, Process Biochem., 2012, 47, 1691-1698.

6 A. Cumashi, N. A. Ushakova, M. E. Preobrazhenskaya, A. D'Incecco, A. Piccoli, L. Totani, N. Tinari, G. E. Morozevich, A. E. Berman, M. I. Bilan, A. I. Usov, N. E. Ustyuzhanina, A. A. Grachev, C. J. Sanderson, M. Kelly, G. A. Rabinovich, S. Iacobelli and N. E. Nifantiev, Glycobiology, 2007, 17, 541-552.

7 M. I. Bilan, A. A. Grachev, A. S. Shashkov, N. E. Nifantiev and A. I. Usov, Carbohydr. Res., 2006, 341, 238-245.

8 M. Nagaoka, H. Shibata, I. Kimura-Takagi, S. Hashimoto, K. Kimura, T. Makino, R. Aiyama, S. Ueyama and T. Yokokura, Glycoconjugate J., 1999, 16, 19-26.

9 L. Chevolot, A. Foucault, F. Chaubet, N. Kervarec, C. Sinquin, A.-M. Fisher and C. Boisson-Vidal, Carbohydr. Res., 1999, 319, 154-165.

10 M. I. Bilan, A. A. Grachev, N. E. Ustuzhanina, A. S. Shashkov, N. E. Nifantiev and A. I. Usov, Carbohydr. Res., 2002, 337, 719-730.

11 M. E. R. Duarte, M. A. Cardoso, M. D. Noseda and A. S. Cerezo, Carbohydr. Res., 2001, 333, 281-293.

12 O. Berteau and B. Mulloy, Glycobiology, 2003, 13, 29R-40R.

13 S. D. Anastyuk, N. M. Shevchenko, E. L. Nazarenko, P. S. Dmitrenok and T. N. Zvyagintseva, Carbohydr. Res., 2009, 344, 779-787.

14 A. I. Usov, G. P. Smirnova, M. I. Bilan, A. S Shashkov and M. Nauka, RUSSIE, FEDERATION DE, 1998.

15 T. Nishino, Y. Takabe and T. Nagumo, Carbohydr. Polym., 1994, 23, 165-173.

16 M. S. Patankar, S. Oehninger, T. Barnett, R. L. Williams and G. F. Clark, J. Biol. Chem., 1993, 268, 21770-21776.
17 N. M. A. Ponce, C. A. Pujol, E. B. Damonte, M. L. Flores and C. A. Stortz, Carbohydr. Res., 2003, 338, 153-165.

18 J. Hemmingson, R. Falshaw, R. Furneaux and K. Thompson, J. Appl. Phycol., 2006, 18, 185-193.

19 H. Maruyama and I. Yamamoto, Hydrobiologia, 1984, 116117, 534-536.

$20 \mathrm{H}$. Kylin in Hoppe-Seylers Zeitschrift für physiologische Chemie, 1913, vol. 83, p. 171.

$21 \mathrm{H}$. Kylin in Hoppe-Seylers Zeitschrift für physiologische Chemie, 1915, vol. 94, p. 337.

22 W. L. Nelson and L. H. Cretcher, Journal of Biological Chemistry, 1931, 94, 147-154.

23 G. M. Bird and P. Haas, Biochem. J., 1931, 25, 403-400.

24 G. Lunde, E. Heen and E. Öy in Hoppe-Seylers Zeitschrift für physiologische Chemie, 1937, vol. 247, p. 189.

25 E. G. V. Percival and A. G. Ross, Journal of the Chemical Society (Resumed), 1950, 717-720.

26 D. R. Hoagland and L. L. Lieb, Journal of Biological Chemistry, 1915, 23, 287-297.

27 W. A. P. Black, E. T. Dewar and F. N. Woodward, J. Sci. Food Agric., 1952, 3, 122-129.

28 H. A. O. Rocha, F. A. Moraes, E. S. Trindade, C. R. C. Franco, R. J. S. Torquato, S. S. Veiga, A. P. Valente, P. A. S. Mourão, E. L. Leite, H. B. Nader and C. P. Dietrich, J. Biol. Chem., 2005, 280, 41278-41288.

29 A. F. Abdel-Fattah, M. M.-D. Hussein and H. M. Salem, Carbohydr. Res., 1974, 33, 9-17.

30 S. Ermakova, R. Sokolova, S.-M. Kim, B.-H. Um, V. Isakov and T. Zvyagintseva, Appl. Biochem. Biotechnol., 2011, 164, 841-850.

31 W. Zhu, V. E. C. Ooi, P. K. S. Chan and P. O. Ang Jr, Biochem. Cell Biol., 2003, 81, 25-33.

32 V. Descamps, S. Colin, M. Lahaye, M. Jam, C. Richard, P. Potin, T. Barbeyron, J.-C. Yvin and B. Kloareg, Mar. Biotechnol., 2006, 8, 27-39.

33 T. Sakai, K. Ishizuka, K. Shimanaka, K. Ikai and I. Kato, Mar. Biotechnol., 2003, 5, 536-544.

34 T. Sakai, H. Kimura and I. Kato, Mar. Biotechnol., 2002, 4, 399-405.

35 M. Bilan, M. Kusaykin, A. Grachev, E. Tsvetkova, T. Zvyagintseva, N. Nifantiev and A. Usov, Biochemistry (Moscow), 2005, 70, 1321-1326.

36 I. Y. Bakunina, O. I. Nedashkovskaya, S. A. Alekseeva, E. P. Ivanova, L. A. Romanenko, N. M. Gorshkova, V. V. Isakov, T. N. Zvyagintseva and V. V. Mikhailov, Microbiology, 2002, 71, 41-47.

37 S.-i. Furukawa, T. Fujikawa, D. Koga and A. Ide, Biosci., Biotechnol., Biochem., 1992, 56, 1829-1834.

38 O. Berteau, I. McCort, N. Goasdoué, B. Tissot and R. Daniel, Glycobiology, 2002, 12, 273-282.

39 H. R. Sørensen, S. Pedersen, C. T. Jørgensen and A. S. Meyer, Biotechnol. Prog., 2007, 23, 100-107.

40 A. S. Meyer, L. Rosgaard and H. R. Sørensen, J. Cereal Sci., 2009, 50, 337-344.

41 S. J. Heo, E. J. Park, K. W. Lee and Y. J. Jeon, Bioresour. Technol., 2005, 96, 1613-1623.

42 A. Holtkamp, S. Kelly, R. Ulber and S. Lang, Appl. Microbiol. Biotechnol., 2009, 82, 1-11.

43 F. Shin-ichi, F. Tatsuo, K. Daizo and I. D. E. Akio, Biosci., Biotechnol., Biochem., 1992, 56, 1829-1834. 
44 T. Sakai, T. Kawai and I. Kato, Mar. Biotechnol., 2004, 6, 335-346.

45 M. T. Ale, H. Maruyama, H. Tamauchi, J. D. Mikkelsen and A. S. Meyer, Int. J. Biol. Macromol., 2011, 49, 331-336.

46 J. Wang, Q. Zhang, Z. Zhang, H. Song and P. Li, Int. J. Biol. Macromol., 2010, 46, 6-12.

47 E. Kim, S. Park, J.-Y. Lee and J. Park, BMC Gastroenterol., 2010, 10, 96.

48 Y. Yamasaki-Miyamoto, M. Yamasaki, H. Tachibana and K. Yamada, J. Agric. Food Chem., 2009, 57, 8677-8682.

49 Y. Aisa, Y. Miyakawa, T. Nakazato, H. Shibata, K. Saito, Y. Ikeda and M. Kizaki, Am. J. Hematol., 2005, 78, 7-14.

50 H. Maruyama, H. Tamauchi, M. Iizuka and T. Nakano, Planta Med., 2006, 72, 1415-1417.
51 T. Teruya, T. Konishi, S. Uechi, H. Tamaki and M. Tako, Int. J. Biol. Macromol., 2007, 41, 221-226.

52 K. Senni, F. Gueniche, A. Foucault-Bertaud, S. IgondjoTchen, F. Fioretti, S. Colliec-Jouault, P. Durand, J. Guezennec, G. Godeau and D. Letourneur, Arch. Biochem. Biophys., 2006, 445, 56-64.

53 T. Fujimura, K. Tsukahara, S. Moriwaki, T. Kitahara and Y. Takema, Effects of natural product extracts on contraction and mechanical properties of fibroblast populated collagen gel, Pharmaceutical Society of Japan, Tokyo, JAPON, 2000.

54 Z.-J. Wang, Y.-X. Si, S. Oh, J.-M. Yang, S.-J. Yin, Y.-D. Park, J. Lee and G.-Y. Qian, Journal of Biomolecular Structure and Dynamics, 2012, 1-14. 